\title{
Productos de la Hispania romana: miel y púrpura
}

\author{
Pilar FERNÁNDEZ URIEL \\ Universidad Nacional de Educación a Distancia \\ pfuriel@geo.uned.es
}

\section{RESUMEN}

Análisis y revisión de la elaboración, empleo y consumo de dos productos utilizados en la Hispania romana: miel y púrpura a través de los testimonios literarios y arqueológicos.

Palabras clave: Miel. Vasa mellaria. Colmenas. Apiarios. Kalathos. Púrpura. Murex. Purpurarii. Tinte púrpura. Sucedáneos.

\section{Products of Roman Hispania: Honey and purple}

\begin{abstract}
Analysis and review of the processing, use and consumption of two products used in Roman Hispania: Honey and purple through literary and archaeological evidence.
\end{abstract}

Key Words: Honey. Vasa mellaria. Hives. Apiaries. Kalathos. Purple. Murex. Purpurarii. Purple. Dye. Substitutes.

Sumario: 1. Apicultura en hispania. 2. Purpura en hispania. 
En la economía de la Hispania augustea y altoimperial, hay dos productos poco conocidos debido a la ausencia de documentación y a las dificultades de su estudio, sin embargo, actualmente están recibiendo una mayor atención. Son dos producciones muy diferentes pero tienen en común la amplia cronología de su existencia en la península. Ubicar el conocimiento de la apicultura y de la púrpura en época romana augustea con los datos que contamos es una tarea prácticamente imposible, es necesario analizar ambas en un contexto cronológico mucho más amplio, en torno al cambio de era y al periodo Alto Imperial, entre los siglos I y II, del que poseemos más documentación. Hay que subrayar que tanto la técnica, como los instrumentos e instalaciones de ambos productos debieron de variar muy poco a lo largo de la Antigüedad.

\section{Apicultura en Hispania}

La miel era una sustancia apreciada por sus múltiples cualidades, y así lo resaltan los autores clásicos, como Virgilio (Églogas, Eneida y Geórgicas, el libro IV ${ }^{\circ}$ está exclusivamente consagrado al cultivo de las abejas, la división del trabajo, organización, obediencia a la reina y sus peculiaridades asombrosas) y la bellísima descripción de Plinio: "un jugo dulcísimo, ligerísimo y salubérrimo (Plinio, Nat Hist. XI 1.5)... que aporta el gran placer de su naturaleza celestial" (Plinio, Nat Hist. XI 1.12). Arraigada dentro de las costumbres culinarias, constituía el alimento energético por excelencia y, además, sus propiedades antisépticas hacían idónea a la miel para ser empleada en la conservación de frutos, en la medicina e incluso en la elaboración de cosméticos (donde sigue vigente su utilización). ${ }^{1}$

Es significativo que los primeros testimonios históricos se encuentran en el sureste peninsular, parecen indicar casi invariablemente que allí surgieron los primeros centros productores. Desde las pinturas parietales prehistóricas del arte levantino, cuyo ejemplo más destacado es el de la Cueva de la Araña en Bicorp. ${ }^{2}$ Sin duda, este primer testimonio de la recolección de la miel y el mito de Gárgoris y Habis tomado de Justino (XLIV 4.1) demuestran que la utilización de la miel, se remonta a una época prehistórica y protohistórica que se vinculó con el mito y la leyenda.

Los testimonios históricos son escasísimos:

\section{Fuentes}

Por lo que respecta a las fuentes literarias contamos con el testimonio aportado por Estrabón: "De turdetanos las exportaciones de trigo, mucho vino y aceite de oliva, no sólo en cantidad sino también en calidad, e incluso de cera, miel, pescado, cochinilla" (Geograph. III 2.6). También Plinio el Viejo (Nat. Hist. XXI y XXII), Columella (De re rustica IX y X) y Varrón (De re rust. III 16).

Este testimonio esta reforzado por fuentes toponímicas: ciudades con topónimos relacionados con la miel se encuentran en el extremo peninsular y norte africano

1 Fernández Uriel 1990, 136; VÁzQUez 1991, 67.

2 HERNÁNDEZ - PACHECO 1924, 88-93. 
(Mellaria/Melissa), que tal vez aludan a un centro productor de cera y miel. En el sur peninsular hay dos localidades hispanas de las que sabemos que llevaban el nombre de Mellaria, una en la comarca de San Roque (Cádiz), donde se producía una miel amarillenta. De allí era el prefecto de la Annona de época augustea: Turranius Gracilis: a vico Mellaria Hispaniae ad promunturium Africae Album, auctore Turranio Gracile iuxta genito (Plinio, Nat. Hist. III 1.3). Otra localidad citada como Mellaria estaba en la serranía cordobesa, en Fuenteabejuna. ${ }^{3}$

"Tierra de la miel". Con este nombre se menciona, en el texto de Artemídoro de Éfeso, que acompaña un mapa de rutas de Hispania en el papiro procedente de la ciudad de Antaéopolis, una tierra extrema de la provincia romana de la Hispania Ulterior, vecina de Gades: "Desde los Pirineos hasta las cercanías de Gadeira y la tierra de la miel, todo el país se denomina igualmente Iberia e Hispania. Los romanos lo han dividido en dos provincias.... a la segunda provincia pertenecen las tierras de Gadeira y toda la región (Kora) de Lusitania". ${ }^{4}$ Este centro productor de miel bártulo turdetano (Ptolomeo II 4.6) se mantuvo en época romana. Incluso es posible que dicha producción se incrementara, como indica E. Gozalbes Cravioto. Resulta muy significativo que recibiera en el siglo II a.C., un nombre plenamente latino que aludía a la riqueza que en ese momento caracterizaba dicho territorio, Mellaria, lugar de miel (Estrabón, Georaph. III 2.6).

Circunstancias paralelas podrían haberse dado en la antigua fundación púnica de Rusaddir (actual Melilla), es citada como Melissa por Hecateo de Mileto, ${ }^{5}$ en el periplo de Hannon. ${ }^{6} \mathrm{Si}$ bien, el origen y la significación de este topónimo y su derivación en el término Melilla son muy discutidos.

Las fuentes iconográficas son escasísimas. Precisamente uno de los escasos documentos iconográficos con los que contamos es la representación de una abeja en el reverso de la moneda rusaditana, ciudad antes citada. ${ }^{7}$ Otra enigmática abeja se encuentra representada en el reverso de una moneda anepígrafa hallada en Augusta Emérita, sin que hasta la fecha se haya logrado su identificación. ${ }^{8}$ Finalmente es notable la otra representación es una pequeña fíbula de oro de $25 \mathrm{~cm}$ con puente depositada en el Museo de Cádiz, procedente de un ajuar femenino de la necrópolis romana de Punta de Vaca, analizada por López de la Orden y fechada en época augustea o julio-claudia (N.I.: CE0043). ${ }^{9}$

El único documento epigráfico sobre la producción de miel conocido hasta la fecha es una tablilla de plomo encerada descubierta en la serranía de Córdoba que cita una occupatio de tierras, presumiblemente de ager publicus, para un colmenar (CIL II, 2242). Se trataría de una locatio silvae et pascua colonorum Coloniae Patriciae, cuyo régimen estaría regulado por la ley fundacional igual que ocurría en Urso, don-

3 Gozalbes 1998; Fernández URIEL 1998.

4 Recogido y analizado en Gozalbes 2001, 105-114.

5 Hecateo de Mileto, frag. 324 y327; Ibidem, Geographica III 55.

6 Müller 1854, 1-14.

7 FERNÁNDEZ URIEL 2004, 147-167.

8 FERnÁndez URIEL 2011.

9 Fernández URiel 2011, 224. 
de se prohibía el alquiler por más de un lustro, pero nada sabemos de sus términos. Volveremos sobre él. ${ }^{10}$

Son las fuentes arqueológicas las que han permitido lograr un mayor conocimiento de la apicultura hispana gracias a los estudios y a la reinterpretación de restos cerámicos. Este avance se ha producido a partir de mediados de la década de los noventa aproximadamente. El estudio de las cerámicas halladas en el registro arqueológico, principalmente en el entorno ibérico, es decir, documentados en el área edetana y albaceteña permitieron no sólo identificar sino clasificar materiales y tipologías cerámicas vinculadas a la labores de apicultura: colmenas, embudos y envases (vasa mellaria) y abrieron el debate sobre la posibilidad de la explotación de la apicultura en otros yacimientos. Efectivamente, van incorporándose poco a poco otros ámbitos de la península como focos productores de miel de los que no se tenía constancia y que demuestran que no hay un solo horizonte geográfico de explotación, tal vez se llegue a admitir que se trata de una de las producciones con mayor área de extensión geográfica, aunque todavía hay un total vacío en una gran parte de las provincias hispanas. Actualmente contamos ya con excelentes investigaciones, en el registro arqueológico, incluso en la arqueología experimental ${ }^{11}$ destacándose los trabajos de Consuelo Mata y Helena Bonet (yacimientos como el oppidum edetano de Puntal dels Llops, Monravana y del Tossal de Sant Miquel y Castellet de Bernabé, ${ }^{12}$ de Fuentes Albero, Hurtado Mullor y Moreno Martín, ${ }^{13}$ Rui Morais ${ }^{14}$ y Almeida y Morín. ${ }^{15}$

\section{Colmenas}

Las colmenas pudieron ser fabricadas con distintos materiales, utilizando para ello las materias primas disponibles en el entorno del yacimiento. Su fabricación se llevó a cabo tanto con materiales perecederos, posiblemente ya utilizados en la Prehistoria (caña, corcho, esparto, estiércol, madera, mimbre, etc.) como imperecederos (cerámica, ladrillo...) (Columela, IX 6; Plinio, Nat.Hist. XXI 1.14), siendo éstos últimos de gran importancia, dado que su conservación y perdurabilidad ha permitido constatar la existencia de apicultura.

Se trata de un tipo de colmenas que actualmente se denominan "fijas" (apicultura fijista) que se disponen en una hilera aislada o apiladas sobre el suelo o sobre un murete construido al efecto. La identificación de las colmenas cerámicas ibéricas se produce a partir de paralelos arqueológicos y etnográficos ${ }^{16}$ de otros lugares del Mediterráneo (la Kabilia argelina, Marruecos, las Islas Baleares y la villa griega de Cave of Pan, en Thasos). Según Bonet y Mata: "Las colmenas cerámicas ibéricas consisten en unos recipientes cilíndricos abiertos en ambas extremidades, con diámetros comprendidos entre los 24 y 29 centímetros, una altura entre 53 y 58 centímetros, y una

10 GonzÁlez Román 1994.

11 BONET - Vives-FERRÁndiz 2011.

12 MATA - Bonet 1992, 1995, 1997, 2002.

13 Fuentes Albero - Hurtado Mullor - Moreno Martín 2004.

14 Morais 2006.

15 Almeida - Morín 2012.

16 Mata - Bonet 1992, 137. 
capacidad de cerca de 48 litros, ${ }^{17}$ "medidas y capacidades coincidentes con las que tradicionalmente se suelen estimar para las romanas y tradicionales". ${ }^{18}$

Presentan una cierta variedad en la tipología de sus bordes en época iberorromana. ${ }^{19} \mathrm{~A}$ estos recipientes se les había atribuido, hasta ese momento, una funcionalidad distinta a la apícola. Debido a sus características morfológicas -forma tubular-, fueron identificadas como soportes o conducciones, sin tener en cuenta la factura de las acanaladuras interiores que fueron consideradas como simples marcas de torno, pero se diferencian bastante de éstas, no solo por su forma. Precisamente estas acanaladuras son el principal elemento que las identifica. Son unas típicas estrías, surcos o acanaladuras incisas, paralelas y profundas, en la práctica totalidad de su superficie interior, realizadas en fresco antes de la cocción, en toda su superficie interior, que tienen como fin una mejor adhesión de los panales.

Actualmente las colmenas de cerámica se van identificando en otros yacimientos peninsulares: tanto en el área albacetense donde Soria Combadiera, en 1999, aportó nuevos datos de colmenas en esta provincia, ${ }^{20}$ como en la cuenca del Júcar, regiones que ampliaron el contexto geográfico de la difusión y uso de esos recipientes a los territorios interiores. En la parte oriental meseteña, concretamente el estudio y clasificación del registro arqueológico perteneciente a los yacimientos del entorno rural (ager) de la antigua ciudad de Segobriga (Cuenca), permiten confirmar la utilización y la producción de colmenas. ${ }^{21}$

En el noroeste de la Hispania Tarraconensis, en la insula de las Carvalheiras en Bracara Augusta (Braga) se ha identificado una pieza cilíndrica, con un diámetro máximo de 17,4 centímetros y mínimo de 13 centímetros, y una altura de 42 centímetros de menores dimensiones que las ibéricas y que las romanas del área de Segobriga.$^{22} \mathrm{El}$ mismo autor menciona que ese ejemplar, que se encontraba depositado en el museo local, fue inicial y erróneamente clasificado como un elemento de tubería.

17 BONET - MATA 1995, 280-281.

18 CRAne 1983, 17, tabla 2.

19 "Se definieron cuatro grandes grupos según sus caracteres formales: $1^{\text {o: }}$ con los bordes engrosados, externa o internamente; $2^{\circ}$ : con los bordes de tipo moldurado; $3^{\circ}$ : con los bordes amplios o pendientes; $4^{\circ}$ : con los bordes salientes simples, un tipo de borde que apenas sobresale, excediendo el diámetro máximo de la pieza. Posiblemente la producción de las colmenas de tipo "borde engrosado" se iniciaría en el Ibérico Pleno, incrementándose a lo largo del Ibérico Final, hasta que en época Imperial se observa su retroceso. En lo relativo a las colmenas con el borde "moldurado", se trata de una forma con altos índices de producción, tanto en el Ibérico Pleno como en el Final, aumentando en este último tanto los yacimientos como el número de fragmentos hallados, y persistiendo en época imperial, aunque en menor número. En cuanto a las colmenas con el "borde pendiente", son escasas en los yacimientos de las áreas edetanas y nulas en la provincia de Albacete, siendo por lo tanto una forma típica del Ibérico Final. Por último, que las de "borde saliente simples" aunque podrían tener un origen en el Ibérico Pleno, se deberían adscribir al Ibérico Final, principalmente debido a su mayor presencia en esta fase en cuanto a número de yacimientos y ejemplares" (FUENTES - HURTADO - MoRENO 2004, 190-194).

20 Soria COMBADIERA 2000.

21 Son los yacimientos: La Peña II (Almeida - López Fraile - Morín de Pablos, 2012), Llanos de Pini1la, Los Vallejos (Morín de Pablos, ed., 2012), Las Lagunas (Almeida - Morín de Pablos, 2012), Casas de Luján II (Morín de Pablos - Urbina, 2012) y Rasero de Luján (Almeida Y Morín de Pablos, 2012b), en los que se pudo recuperar no solo una gran cantidad de fragmentos de bordes, cuerpos y fondos, que testimonian el uso de las colmenas cerámicas.

22 Morais 2006, 157. 
Con gran probabilidad, muchas aún se encontrarán erróneamente clasificadas en el registro cerámico bajo la designación de tuberías.

Rui Morais, ante la ausencia generalizada de este tipo de recipientes cerámicos en los inventarios peninsulares, realizó una síntesis sobre la problemática de la miel y de la revisión de cerámicas no identificadas o deficientemente clasificadas que pudieran estar relacionadas con las labores apícolas, con su producción y almacenamiento en territorio peninsular. Se deben revisar muchos fragmentos tradicionalmente clasificados como canalizaciones cerámicas, su identificación y recopilación en las provincias hispanas. Estos nuevos datos permitirían cuantificar y valorar debidamente, en base a los vestigios arqueológicos, la producción y comercialización de la miel y avanzar en el conocimiento de la cultura apícola, también presumir que la apicultura fue una actividad más generalizada y con mayor potencia e importancia económica que la que entonces se suponía.

\section{Embudos}

En años anteriores, J. Molina García ya había analizado embudos hallados en el yacimiento de Coimbra del Baranco Ancho (Jumilla, Murcia), con la siguiente descripción: "tipo cerámico de escasa conicidad y profundidad, tan llanos o abiertos como platos". ${ }^{23}$ Se trata de embudos que presentan escasa conicidad y gran apertura, con determinados caracteres que no tenían paralelo alguno en la tipología ibérica conocida, y el autor sugirió que pudieran aplicarse a las actividades apícolas. Sus determinadas características no les hacían válidos para la acción de verter y recoger sobre él cualquier líquido que habría de ejercerse con sumo cuidado a fin de evitar su derramamiento por el lado contrario. Pero sí eran adecuados para un líquido denso, viscoso como la miel, es decir, se trataría de un embudo para verter la miel.

\section{Recipientes (vasa mellaria)}

Son recipientes de diversas formas y capacidad, varían entre 1 a 16 litros. Hay que tener presente que la miel, además de alimento, era empleada para otros usos muy variados. Ello repercutía en el volumen de sus envases, de mayor tamaño para su almacenamiento una vez recolectada y otros de tamaño menor e incluso muy decorados. Interesa aquí de forma particular la posibilidad de que los típicos recipientes cerámicos tipo kalathoi (vasos cilindroides de borde saliente moldurado y base cóncava) sirviesen de vasa mellaria, especialmente por su propio diseño, con asas muy pequeñas, amplia boca y fondo estable que refuerzan su interpretación como vaso de almacenaje y aconsejan su mantenimiento en una posición fija dentro de la vivienda. Una hipótesis a la que contribuye el hecho de que posea decoración, lo que implica su exposición y visualización. ${ }^{24}$

23 Molina García 1989.

24 Bonet - Vives-Ferrándiz 2011, 289-291. S. Nordström (1969, 178-180), fue quién primero acuñó para estos vasos el nombre de Kalathos, haciendo derivar la forma cerámica de un cesto de mimbre de proce- 
La funcionalidad del kalathos ha preocupado a los investigadores desde hace décadas ya que resultaba difícil atribuirle una función específica debido a su especial tipología. Su amplia boca con un resalte muy saliente en forma de "pestaña" podría servir para contener agua, con la finalidad de refrigerar o, más probablemente, para evitar el alcance de insectos, además podía recoger lo que se escapase y así evitar que se derramase por las paredes. La primera referencia fue ya proporcionada por $\mathrm{D}$. Fletcher en $1953 .{ }^{25}$ Más tarde, S. Broncano y J. Blázquez ${ }^{26}$ y yo misma ${ }^{27}$ sugerimos que recipientes con estas características podrían servir para contener líquidos densos como aceite o miel. Sin duda no son los únicos, hay otros recipientes de tipología semejante autentificados como envases de miel. Manuela Delgado, a propósito del descubrimiento de recipientes de época romana en el yacimiento de Bracara Augusta, analizó su analogía con los recipientes de algunas regiones de Portugal y Galicia, permitiendo reconocer que, además de otros fines, tendrían como función guardar miel y aceite. ${ }^{28}$

\section{Los apiarios}

Con los datos que contamos actualmente resulta difícil refrendar, pero sí sugerir, cuestiones tan importantes como la situación, ubicación y explotación de los apiarios, así como su relación con la agricultura, limitándonos a la época augustea, realizando estudios paralelos pues sobre la explotación apícola solo tenemos testimonios de época imperial posterior. Dichas cuestiones se podrían sintetizar en dos puntos:

a) ¿Estaba la apicultura vinculada con la producción agrícola?

Así parecen sugerir los comentarios de Plinio, Estrabón (Estrabón, Geograph. III 2.6.1; Plinio, Nat.Hist. 16.21.82) y más tarde los tratados de Varrón y Columella (siglo II). Varrón (De re rust. III 16) trata de los terrenos utilizados para la explotación de miel y parece que eran rentables trasformando una parte del campo en zona apícola y cultivando allí las plantas apropiadas, como lo fueron en otras zonas del Imperio. Comenta Plinio acerca de la producción de miel en la Península:

"Las abejas hacen los panales de las flores de todos los árboles y plantas, menos de la acedera y de la buglosa. Equivocadamente se exceptúa también el esparto, ya que en Hispania muchas variedades de miel recogidas en espartales saben a esa planta. También creo que se exceptúan equivocadamente los olivos, ya que es cierto que la mayoría de los enjambres se originan donde son abundantes las aceitunas".

Plinio, Nat.Hist. II 8.18

\footnotetext{
dencia griega como sugieren implícitamente los paralelos iconográficos buscados por la autora sueca así como la misma palabra Kalathos.

25 Fletcher Vals 1953.

26 BRONCANO - BLÁZquez 1985, 273.

27 FERNÁNDEZ URIEL 1990.

28 Delgado 1996-97, 149-165.
} 
Según este texto, la producción de la miel podría estar relacionada con otra fundamental en el campo bético: la del aceite, que ya analizaron P. Sáez Fernández y Genaro Chic. Llamaban la atención sobre un texto en el que Columela recomienda la producción alterna, y que el olivar se divida en dos partes para cada año de cosecha, "con lo que indirectamente nos está diciendo que se aprovechara como pastos o rastrojeras la parte que no produzca ese año". ${ }^{29}$

b) ¿En qué condiciones?

Según Varrón quienes poseían colmenas en régimen de aparcería tenían que entregar anualmente a los dueños o a los arrendatarios un sextario $\left(0^{\prime} 547\right)$ de miel por cada una (Varrón, De re rust. III 16.10). Recordemos que el único documento epigráfico sobre la producción de miel conocido hasta la fecha es una tablilla de plomo encerada descubierta en la serranía de Córdoba que cita una occupatio de tierras, presumiblemente de ager publicus, para un colmenar (CIL II, 2242), analizada por J. F Rodriguez Neila. Se trataría de una locatio silvae et pascua colonorum Coloniae Patriciae, cuyo régimen estaría regulado por la ley fundacional igual que ocurría en Urso, donde se prohibía el alquiler por más de un lustro, pero nada sabemos de sus términos:

L(ucio).Valerio. Poen(o). Antistio.Rustico/IIvir(is)/a(nte) d(iem) III K (alendas)septembres/L(ucius).Valerius C(ai) f(ilius).(K) apito alvari locum occupavit ${ }^{30}$

c) ¿Apicultura trashumante?

G. Chic analizó el contexto económico de la apicultura bética y propuso la sugerente hipótesis de la práctica de la apicultura trashumante, todavía en uso en algunas regiones de España, como en la provincia de Guadalajara. ${ }^{31}$ Consideró la famosa cita de Plinio sobre la utilización de las bestias de carga, que según este autor dicha costumbre se practicaba también en Hispania, haciendo viajar las colmenas instaladas sobre mulos pero no indica un lugar determinado: In Hispania mulas simil provehunt. Refret tamtumque pábulo mella quoque fiant ut venenata (Plinio, Nat.Hist. XXI 74-75). ${ }^{32} \mathrm{Co}-$ lumela recomienda, que el traslado se haga de noche para no perturbar a las abejas y Celso alude a la trashumancia con el cambio de las estaciones.

"Aman [la abejas] los lugares de pasto habituales y no van voluntariamente a otros extraños, por lo cual se las debe mantener en la zona. Pero si forzosamente hubiera que trasladarlas, porque alguien las compre o por alguna otra causa, han de ser sacadas antes del amanecer, de noche y con delicadeza, envolviendo los cajones con pieles, pues si lo haces con sigilo no agitaras las colmenas ni perturbaras a los animales".

Columela, De re rust. $9.8 .3^{33}$

\footnotetext{
29 SÁEz Fernández 1991, 289; ChiC García 1994, 183.

30 Rodríguez NeILA 1994, 25-460.

31 Castellote Herrero 1978.

32 Chic García 1990.

33 Geopónica 15.2.10-11.
} 
$\mathrm{Al}$ respecto, es importante el comentario de Celso:

"Como en pocas partes hay la felicidad de que se puedan dar a las abejas unos pastos de primavera y otros en el estío, en los parajes donde pasada la primera estación faltan flores a propósito para las abejas, no deben dejarse las colmenas, sino que así que se hayan consumido estas flores, se han de trasladar a aquellos que puedan mantener las abejas mejor con las flores tardías de tomillo, de orégano y de mejorana silvestre"

Celso, De re rust. 11.14.

Sobre este tema también hay cuestiones como la forma de trasporte de las colmenas, los recipientes utilizados en su traslado (odres o cerámica). El profesor G. Chic, en su trabajo citado sobre las abejas, plantea si la miel podría haber sido trasladada en odres. Los odreros tenían que poner a disposición del público para su alquiler cueros para el acarreo de vino, aceite, agua y miel, estos sensiblemente más caros. ${ }^{34}$

En realidad no tenemos ningún testimonio sobre la utilización de los odres como envases en la Hispania antigua, lo cual no quiere decir en absoluto que no se empleasen. Envase muy ligado a la vida de pueblos pastores y ganaderos, lo tenemos atestiguado como flotador usado por los hispanos tanto en la travesía del Ródano acompañando a Aníbal (Livio XXI 27.5) como en la campaña de César en la Citerior (B.C. I 48.7). Sería absurdo pensar que esta era su única utilidad. Y además, en la misma línea Plinio, nos dice:

Pix in Italia ad vasa vino condendo maxime probatur Bruttia. Fit e piceae resina, in Hispania autem e pinastris minime laudata Est enim resina harum amara et gravis odore.

Plinio, Nat.Hist. XIV 127

Pero las costuras de los odres se untaban con pez y por tanto no permitían la introducción de determinadas sustancias que podrían deteriorar su calidad en cuanto a olor y sabor, por lo que sería más probable que se trasladara la miel en tinajas de barro. ${ }^{35}$ Los estudios realizados en el área edetana han permitido descubrir e incluso reinterpretar el registro arqueológico cerámico relacionado con la actividad apícola como una actividad difundida en las provincias hispanas, una producción con cierto auge, incluso rentable, conocida y controlada y orientada como una tarea más del calendario agrícola, y no como se venía interpretando como una actividad complementaria.

\section{Purpura en Hispania}

Otra riqueza económica muy poco analizada fue la fabricación y comercio del tinte púrpura en la península en época augustea y altoimperial. Dicha fabricación requería unas instalaciones más complejas donde se cubrieran unas necesidades precisas.

34 Chic García 1988.

35 Lillo Carpio 1994. 
Atendiendo a éstas y al proceso de fabricación, puede realizarse una reconstrucción de su adecuada infraestructura, valiéndonos de la información de Plinio y los modelos que nos han proporcionados los descubrimientos arqueológicos.

En este caso se necesita una ubicación más determinada debido a que la materia prima, los múrices purpúreos (Hexaplex Truncullus, Murex Brandaris, Purpura Aemastoma) cuya abundancia en las costas ya era conocida y citada por los antiguos, tenía que ser utilizada viva o de forma inmediata, fundamentalmente, para que no perdiese ni alterase sus cualidades. Lo más probable es que se realizase la fabricación del tinte en lugares muy cercanos a la manipulación de los múrices. Por lo que se deduce que las factorías purpurarias se hallaban en el litoral costero, incluso asociadas a un embarcadero y próximas a las vías de comunicación terrestre y marítima. De hecho, la casi totalidad de los escuetos testimonios arqueológicos sobre la fabricación de púrpura en la zona levantina y meridional se relaciona en realidad no con instalaciones exclusivas de confección de púrpura, sino más bien con talleres de mayor tamaño dedicados también a la salazón del pescado y a la fabricación de salsas saladas (cetaria). Es posible que esta pesca se extendiese a estos múrices, un dato digno de considerar a la hora de reconstruir el "circuito económico" de la púrpura y su importancia en el conjunto de la economía marítima.

En la península Ibérica, las factorías de púrpura tienen una ubicación muy definida donde debió tener importancia económica la producción del tinte desde época fenicia y púnica. Todas estas zonas reúnen las condiciones idóneas para desarrollar actividades relacionadas con el mar: cercanas a la playa, con embarcadero y con vientos dominantes que aliviarían en cierto modo los fuertes olores que desprenden este tipo de actividades, buscándose en definitiva unas condiciones óptimas de salubridad. Esta fabricación se podía ubicar en dos ámbitos geográficos determinados: Levante Mediterráneo (Ibiza y Cartagena) y el Circulo del Estrecho de Gibraltar (Carteia, Huelva, zona atlántica).

\section{Levante Mediterráneo (Ibiza y Cartagena)}

En la zona levantina, concretamente en el entorno del Cartagena, la antigua Carthago Nova, posiblemente la explotación de púrpura tendría un origen púnico, continuado en época romana. Un testimonio que confirmaría esta hipótesis son los restos malacológicos del entorno de Cartagena, analizados por E. Tebar y el taller de fabricación de púrpura hallado en el contexto global del asentamiento romano de Águilas (Murcia), excavado por Juan de Dios Hernández García cuya publicación proporciona una valiosa información.

Esta factoría de producción de tinte de origen marino se construyó durante época de Augusto, sobre el cambio de era y estuvo en funcionamiento durante el siglo I d.C., coincidiendo con el desarrollo urbanístico y edilicio de la población, en su zona costera, donde se han exhumado estructuras que indican un marcado carácter industrial. Estrabón y Plinio hacen importantes referencias a la pesca y fabricación de púrpura en las islas Baleares. Las condiciones de estas costas y la abundancia de múrices productores de tinte, su ubicación en el Mediterráneo y sus islas son un lugar idóneo para la implantación de factorías dedicadas a la producción de púrpura. 
Ya en el siglo pasado el investigador Lacaze-Duthiers descubrió en Mahón la abundancia del Purpura Haemastoma, que daba un tinte violáceo a las ropas de los pescadores. En la isla de Ibiza ya se conocía la presencia de algunos concheros formados por la acumulación de fragmentos de moluscos. A partir del año 2001 se llevaron a cabo investigaciones para conocer la industria purpúrea en la zona, relacionándola con el Mediterráneo occidental.

La segunda campaña arqueológica realizada en el yacimiento de Pou des Lleó -Canal d'En Martí, al norte de la isla, (octubre-noviembre de 2002), puso al descubierto unas estructuras aptas para esta fabricación. Además de fragmentos cerámicos, apareció una gran acumulación de restos de malacofauna: Hexaplex Trunculus y Purpura Haemastoma, así como otras especies minoritarias propias de la fauna marina local, (Cerithium Vulgatum, Osilinus Turbinatus). Es importante el conjunto de canalización de las cubetas y el notable registro arqueológico que, analizado, permite la datación cronológica (cerámica de importación africana, ánforas púnico busitanas PE-25, sigilatas y otras producciones locales junto con fragmentos de vidrio y algunos clavos de bronce), ofreciendo una larga secuencia cronológica para esta factoría, que posiblemente estaría en activo durante toda la época augustea y alto imperial romana, (es posible que esta factoría se mantuviera en funcionamiento entre los siglos III y IV d.C.). ${ }^{36}$

\section{Circulo del Estrecho de Gibraltar}

En esta área determinada, en torno al llamado "Círculo del Estrecho de Gibraltar", así acuñado por el profesor M. Tarradell y analizado por otros especialistas, se configuraría un emporio comercial con fines de autoabastecimiento y de relaciones comerciales con una economía un tanto diversificada y una cierta autonomía mercantil, apuntando a un amplio espectro industrial y comercial hacia el Mediterráneo. Los dos grandes centros en torno a los que se situaba esta importante área de desarrollo eran Lixus y Gades, con una magnífica situación geográfica, en torno a la que se ubicaban estas áreas de desarrollo en las que la pesca, la sal y la púrpura constituyeron sin duda factores decisivos y significativos. Ambos centros de tradición fundacional fenicia, estaban íntimamente relacionadas con el culto a Heracles-Melqart, cuyos templos jugaron un importante y decisivo papel en la vida religiosa y económica de esta zona. No deja de ser significativo que a tal divinidad se atribuyera la invención del tinte purpúreo, cuya túnica, según Ovidio, era de púrpura maura, es decir, originaria del extremo occidental. (Ovidio, Fasti II 319).

Allí está probada la existencia de importantes centros de producción, gracias a la investigación de notables yacimientos donde se conocen restos bien identificados y estudiados como talleres de púrpura donde la presencia y utilización de los moluscos purpúreos ya era atestiguada en las fuentes literarias, demostrado por las más recientes excavaciones arqueológicas y confirmado en los análisis biológicos efectuados. Aún así resultan insuficientes. ${ }^{37}$

36 Alfaro Giner - TéBar Megías 2004, 196 ss; Torres 2004, 166-167; Costa - Moreno 2004, 176-178.

37 Chamoro Moreno considera que el Bolinus Brandaris es muy abundante en la zona del estrecho de Gibraltar y A. Morales y E. Roselló en su estudio biológico sobre la zona, destacan la riqueza y los recursos 
Apenas puede contarse con los testimonios que aporta la epigrafía pues solo son dos los purpurarii béticos, ya de época romana que se conocen gracias a dos inscripciones funerarias, procedentes una de Cádiz (CIL II, 1743), que parece mencionar a una purpuraria y la otra de Córdoba (CIL II, 2235), en la que sí es evidente que menciona a un purpurarius. ${ }^{38}$ La cita de Estrabón referente a Carteia es un importante testimonio a valorar:

"Dícese que en Carteia se han hallado buccinas y múrices que pueden contener hasta diez $<$ kotilai $>$ (medida de capacidad equivalente a 0 '25 1.). Y en las costas de afuera $<$ Océano Atlántico $>$, se pescan murenas y congrios de más de ochenta minas, pulpos de un talento de peso, calamares de dos codos de longitud y así por el estilo"

Estrabón, Geograph. III 145

Es fundamental la identificación del taller de púrpura de Carteia donde se demuestra una persistencia en el proceso de fabricación del tinte desde época púnica a la tardoantigüedad. En el propio centro urbano y en la Bahía de Cádiz las recientes excavaciones de urgencia acometidas por un equipo de la Universidad Autónoma de Madrid y la Universidad de Cádiz durante el año 2005, en la zona extramuros de Carteia, han proporcionado las primeras evidencias arqueológicas de producción de púrpura en la Bahía de Algeciras en la Antigüedad Tardía. Se trata de una zona periférica de la ciudad hispanorromana vinculada a la explotación industrial, en la cual durante época alto imperial estuvo en funcionamiento un barrio alfarero de gran envergadura asociado a un embarcadero.

No siendo suficiente la materia prima recolectada en la costa meridional, se recolectó en las rutas atlánticas desde época fenicia. ${ }^{39}$ Así puede ser interpretada la información que ofrecen las fuentes literarias como parecen indicar las descripciones de Avieno y Diodoro, (Avieno, Ora Maritima 97.1; Diodoro, 5.7) que, avaladas por una serie de testimonios arqueológicos en los últimos años, confirman los contactos y las relaciones entre el sur peninsular y las costas gallegas (Estrabón, Geograph. II 5.11).

Los estudios que realizaron A. Coelho Ferreira y J. M. Vázquez Varela sobre la composición y tipología de la fauna marina de los antiguos concheros del norte atlántico, demostraron la abundancia de los múrices purpúreos en las costas portuguesas y gallegas, en especial las especies de Nucella Lapillus y Purpura Haemastoma, que ya fueron recogidos y utilizados en la Antigüedad. Al no haberse encontrado instalaciones adecuadas en torno a las costas atlánticas (como la presencia de depósitos, lacunae o contenedores) que pudieran tener visos de ser utilizadas para la elaboración de la púrpura, muy posiblemente estos murícidos recogidos en las costas gallegas, o el propio líquido purpúreo preparado y macerado (no el tinte) pudieron ser transportados a la zona meridional de la península donde se encontraban talleres y establecimientos adecuados para la manufactura textil de la púrpura. Por ello es importante el dato aportado por Plinio sobre la pervivencia de los múrices durante un tiempo una vez pescados:

\footnotetext{
de la pesca, entre ellos los múrices purpúreos como factores fundamentales de la colonización fenicia en la península ibérica Siret 1907; Garrido Roiz 1988; Chamorro Moreno 1988; Morales - Roselló 1988.

38 FERNANDEZ URIEL 2010.

39 GonZÁlez WaGNER 1988.
} 
"Los múrices, una vez capturados vivos se pliegan en sus conchas y pueden sobrevivir hasta cincuenta días alimentándose de su propia "saliva", de restos de líquenes y algas marinas que queden adheridos a las mismas. Incluso, pueden ser reanimados, simplemente, con el contacto del agua del mar"

Plinio, Hist.Nat. IX 126

Una vez extraído el líquido de las glándulas purpúreas de estos moluscos y macerado en agua salina, podían permanecer el tiempo necesario, al menos dos o tres días que durara la navegación a Carteia y a determinados centros de producción como los que se hallaban en el círculo del Estrecho de Gibraltar, sin que esta preciada materia prima sufriera ninguna alteración. Las excavaciones realizadas en los años 1968, 1970-71 y 1995, en la zona septentrional, ya en la zona portuguesa han permitido hallar abundantes conchas de múrices purpúreos, junto con estructuras adecuadas (compartimentos de tinas o cubas) algunas de ellas con cierres herméticos. ${ }^{40}$ Se ha supuesto que, o bien se elaboraría la púrpura, o se almacenaría el líquido pertinente (liquor, sucus) y los restos de los múrices machacados y macerados en sal para su envío. Es posible que esta púrpura semielaborada pudiera ser transportada a la urbe de Olissipo (Lisboa) y de allí a Roma.

Resulta también significativo que la actual ciudad de Huelva se encuentre ubicada sobre ciertas elevaciones que reciben el nombre El Conquero o Conchero, ${ }^{41}$ que alude a la abundancia de múrices en las costas de la ría de Huelva. Ya el profesor Juan Pedro Garrido encontró en el túmulo 1 de la necrópolis de La Joya, entre otros elementos, restos de Bolinus Brandaris y Hexaplex Trunculus. Su uso funerario parece indicar una sacralización de la actividad técnica y de la riqueza que se lograba con el múrice. $^{42}$

Vinculada a la fabricación purpúrea en esta zona en torno al círculo del Estrecho de Gibraltar se encuentre el litoral atlántico africano del que simplemente citaré la famosa púrpura de Getulia. Esta famosa púrpura africana era producida en las tintorerías fundadas por rey Juba de Mauritania, en torno a principios del siglo I d.C. y el año 40 d.C. cuando Ptolomeo, hijo y sucesor de Juba II fue ejecutado por orden de Gayo Calígula. Según la famosa narración de Dión Casio y, sobre todo de Suetonio, se mantuvieron, siendo explotadas por el Estado romano. ${ }^{43}$

"Había llamado a Roma al rey Ptolomeo < de quien antes hablé> y lo recibió con mucha agasajo, pero un día en que daba Juegos, le hizo matar, de improviso, por el sólo delito de haber llamado la atención general, al entrar en el teatro, por el brillante color púrpura de su manto.”

Suetonio, Vita Caius 35

\footnotetext{
40 Bernal Casasola - Roldán Gómez - Blánquez Pérez - Díaz Rodríguez - Prados Martínez 2008.

41 Chamorro Moreno 1988; Morales - Roselló 1988.

42 GARRIDO - ORTA 1994.

43 Beltrán1960; Mangas 1988. Sobre Ptolomeo de Mauritania son decisivos los estudios de CARCopino 1943, 191 y más recientemente Faur 1973; Kotula 1964; Gozalbes Cravioto 2005.
} 
Entre los motivos más importantes sin duda de la anexión definitiva del reino de Mauritania, se encontraría la posesión y el control de la fabricación y comercio de la púrpura de Getulia. Sin embargo, sólo conocemos históricamente las posteriores alusiones de autores de la época romana que nos hablan de la calidad de la púrpura gétula, allí fabricada. Como casi todos los centros de producción y comercio de púrpura permanecieron en actividad floreciente hasta el final del Imperio Romano, pues la fabricación y comercio de la púrpura fue un considerable monopolio estatal.

No se ofrece una referencia exacta sobre su situación, tan solo que se encuentran frente a los autololes.

“... y no hay historia más cierta de las islas de Mauritania: sólo hay constancia de que se encuentran unas pocas frente a los autololes, descubiertas por Juba, en las cuales había ordenado que se tiñese la púrpura getúlica"

Plinio, Hist Nat. VI 20.1

Es muy posible que se pueda identificar con los islotes de Mogador (Essaouira), que están frente a la ciudad costera africana de ese nombre situada a una latitud algo más alta que la de Canarias, donde se han hallado restos producto de la explotación de tales moluscos para la obtención de la púrpura. Así parecen confirmarlo los hallazgos arqueológicos que han documentado abundantes caparazones de estos moluscos, ratificando de esta forma la procedencia animal de los tintes africanos. ${ }^{44}$

Estas islas, situadas frente a la costa atlántica, son citadas en la geografía de Ptolomeo y, como ya sugerían J. Desjacques y P. Koerbelé, fueron plenamente conocidas por los antiguos ya que se encuentran en la ruta de Gibraltar a las costas de África, muy frecuentada por los navegantes gaditanos y lixitas y, con toda probabilidad explotarían sus riquezas pesqueras, entre ellas, los murícidos que según estos autores eran recolectados por los indígenas como alimento en la Antigüedad. ${ }^{45}$ Sin embargo debido a la pobreza del suelo de arenisca y a la fuerte erosión marina que sufren sus costas no han podido hallarse ni los característicos montones de conchas de moluscos ni construcciones anteriores a las identificadas como las instalaciones de hábitat edificadas en tiempos de Juba II.

Las excavaciones arqueológicas en la zona de Mogador realizadas por M. Tarradell y A. Jodin demostraron la existencia de una clara presencia fenicia desde al menos el siglo VII a.C., con vestigios de cerámica griega (jónica y ática) que facilitan su datación. Utilizaron las instalaciones indistintamente tanto para la fabricación de púrpura como de salazones, aprovechando de esta manera la abundante riqueza que ofrece el mar en esta costa atlántica que, incluso en nuestros días, supone los principales recursos de esta parte de Marruecos. La púrpura debió de tener una enorme importancia en torno al siglo I y posiblemente la fabricada en Getulia alcanzara una notable posición en este mercado.

44 JoDIN 1967.

45 P. Vidal de la Blanche, J. Carcopino y S. Gssel identificaron los islotes que se hallan frente a Mogador con las islas purpurarias e indicaban la abundancia del múrice de la especie Thais Haemastoma en la llamada playa de Safi, aunque no se encuentra aislado pues también en la costa rocosa hay otras especies de murícidos,(Hexaplex Trunculus), aunque en menor cantidad. (VIDAL LA Blanche 1902; CARCOPINO 1947; GSELL 1927). 
Vinculados con el tinte púrpura, que como todos los productos de calidad, tuvo sus sucedáneos, se fabricaron otros tintes substitutivos, de coloridos semejantes, pero nunca iguales, ni en su matiz ni en su calidad ni en su belleza y, por supuesto, en su precio, pero que permitieron un mercado estable y próspero que se debe tener en consideración. Plinio el Viejo relata que con cierta frecuencia los tejidos solían sumergirse en un primer baño de otra tintura antes de tintar con la púrpura de calidad e incluso, con frecuencia mezclaban en su fabricación el líquido purpúreo con otros tintes sucedáneos accesibles, más baratos, que ofrecían un bello colorido por sí mismos por lo que sin duda fueron populares que tuvieron mucha mayor difusión y uso que la exclusiva púrpura y por tanto su fabricación alcanzaría una gran demanda en el mercado, lo que permite sugerir que su papel en la economía de la Antigüedad fue notable y se fabricó en Hispania en el periodoalto imperial.

Otras tinturas que tuvieron un importante mercado fueron el tinte de naturaleza vegetal, el añil o índigo, la Orchilla, orchella (roccella L. del liquen), especie de musgo que se cría en los poros de los riscos, peñas y paredones del mar. Finalmente, la cochinilla (Coccum o Kermes Cocceiius = escarlata) origen del tinte carmesí o escarlata llamado tinte cochinilla Está documentada su recolección en Mauritania, Córcega y sur de Italia, y en puntos de la costa levantina y meridional hispana, en torno a Gades y Malaca. Recibió las alusiones más significativas y abundantes de los autores latinos (Plinio, Hist.Nat. XVI 32; Horacio, 2.6.102; Silio Itálico, 17.395). Fue Estrabón quien enumeró acertadamente los productos y los recursos naturales que se exportaban en la Turdetania, la miel, la cera, la cochinilla. Productos que formaron parte de la riqueza económica de la Hispania augustea:

"Se exporta de Turdetania mucho trigo, vino y aceite, no sólo en cantidad sino también muy bueno. También se exporta cera, miel, pez, mucho kermes (cochinilla) y almagre, que no es inferior a la "tierra de Sinope"..."

Estrabón, Geograph. III 2.6

\section{BibLiOgRAFÍA}

Alfaro Giner, C. - TéBar Megías, E. (2004): “Aspectos históricos, económicos y técnicos de la producción de púrpura en la Ibiza romana", [en] C. Alfaro - J. P. Wild - B. Costa (eds.), Purpureae Vestes I. Textiles y tintes del Mediterráneo en época romana. Actas del I Symposium Internacional sobre Textiles y Tintes del Mediterráneo en época romana (Ibiza 8 al 10 de noviembre, 2002), Valencia, 195-210.

Beltran, F. (1960): "Iuba II y Ptolomeo de Mauritania Ilviri quinquenales de Cartagonova", Caesaraugusta 51-52, 21-39.

Bernal Casasola, D. - Roldán Gómez, L. - Blánquez Pérez, J. - Díaz Rodríguez, J. J. - Prados Martínez, F. (2008): "Del marisqueo a la producción de púrpura. Estudio arqueológico del conchero tardorromano de Villa Victoria/Carteia (San Roque, Cádiz)" [en] D. Bernal Casasola (ed.), Arqueología de la pesca en el Estrecho de Gibraltar. De la prehistoria al fin del Mundo Antiguo, Cádiz, 199-259. 
BlÁZqueZ, J. M.

(1999): Mitos, dioses, héroes, en el Mediterráneo antiguo, Madrid.

(2004): "La explotación de la púrpura en las costas atlánticas de la Mauritania Tingitana y Canarias. Nuevas aportaciones", Anuario de Estudios Atlánticos 50, 689-704. (Versión digital, Gabinete de Antigüedades de la Real Academia de la Historia, 1-9).

Bonet, H. (1995): El Tossal de Sant Miquel de Llíria. La antigua Edeta y su territorio, Valencia.

Bonet, H. - MATA, C.

(1995): “Testimonios de apicultura en época ibérica”, Verdolay 7, 277-285.

(1997): "The Archaeology of Beekeeping in Pre-Roman Iberia", Journal of Mediterranean Archaeology 10/1, 33-47.

(2002): El Puntal dels Llops. Un fortín edetano, (=Trabajos Varios del SIP 99), Valencia.

Bonet, H. - Vives-Ferrándiz, J. (eds.) (2011): La Bastida de les Alcusses. 1928-2010, Valencia.

Broncano, S. - Blánquez, J. J. (1985): El Amarejo (Bonete, Albacete), (=Excavaciones Arqueológicas en España 139), Madrid.

Carcopino, J. (1943): Le Maroc Antique, Paris.

CArrasco Porras, M. S. (2004): "Estudio malacológico de las especies vinculadas a la explotación de la púrpura halladas en Carthago-Nova ( $2^{\mathrm{a}}$ mitad del s. III a.C. - I d.C.)", [en] C. Alfaro - J. P. Wild - B. Costa (eds.), Purpureae Vestes I. Textiles y tintes del Mediterráneo en época romana. Actas del I Symposium Internacional sobre Textiles y Tintes del Mediterráneo en época romana (Ibiza 8 al 10 de noviembre, 2002), Valencia, 211-214.

Castellote Herrero, E. (1978): "Etnografía de la miel en la provincia de Guadalajara", RArchBiblMus 81, 363-408.

Chic García, G. (1994): “La proyección económica de la Bética en el Imperio romano. (Época altoimperial)" [en] Actas II Congreso de Historia de Andalucia, 3, Historia Antigua, Córdoba, 173-199.

Chamorro Moreno, S. (1988): “Conchas de moluscos y otros restos asociados a yacimientos arqueológicos de Ceuta y sus alrededores", [en] Actas del 1.o Congreso Internacional El estrecho de Gibraltar, tomo 4, Madrid, 473-493.

Chic García, G. (1997): “La miel y las bestias”, Habis 28, 153-166.

Conde Berdós, M. J. (1992): "Una producció ceràmica característica del món ibèric tardà: el kalathos"barret de copa", [en] Fonaments. Prehistòria i Món Antic als Països Catalans 8, 117-169.

Costa, B. - Moreno, S. (2004): "La producción de porpra en època romana a Ebusus. Excavacions al jaciment arqueològic de Pou des Lleó/Canal d'en Martí (Eivissa, Illes Balears)”, [en] C. Alfaro - J. P. Wild - B. Costa (eds.), Purpureae Vestes I. Textiles y tintes del Mediterráneo en época romana. Actas del I Symposium Internacional sobre Textiles y Tintes del Mediterráneo en época romana (Ibiza 8 al 10 de noviembre, 2002), Valencia, 175-193.

CRANE, E.

(1983): The Archaeology of beekeeping, London.

(1999): The world history of beekeeping and honey hunting, London.

de Almeida, R. R. - Morín de Pablos, J. (2012): “Colmenas cerámicas en el territorio de Segobriga. Nuevos datos para la apicultura en época romana en Hispania”, [en] D. Bernal 
Casasola - I. Ribera - A. Lacomba (eds.), Cerámicas hispanorromanas II Producciones regionales, Cádiz, 725-741.

Delgado, M. (1996-97): "Potes meleiros de Bracara Augusta”, Portugalia. Nova série 17-18, 149-165.

FAur, J. C. (1973): “Caligula et la Maurétanie: la fin de Ptolémée”, Klio 55, 249-71.

FERNÁNDEZ URIEL, P.

(1992): “Algunas consideraciones sobre la miel y la sal en el extremo mediterráneo occidental", [en] Actas del. Congreso Internacional Lixus, bilan et perspectives. Tanger 7-11 Nov. 1989, (=Collection de l'École Française de Rome 166), Roma, 325-336.

(1993). "Nuevas aportaciones sobre la apicultura en la Hispania antigua", [en] Actas del II Congreso peninsular de Historia antiga. Coimbra, 18 a 20 de outubro de 1990, Coimbra, 955-970.

(1995): “La púrpura en el Mediterráneo Occidental”, [en] Actas del II Congreso Internacional "El Estrecho de Gibraltar" (Ceuta, 1990), Madrid, 309-328.

(2004): "Representación y simbolismo de las abejas en la numismática antigua", Akros 3, $27-40$.

(2004): "La moneda de Rusaddir. Una hipótesis de trabajo", Gerión 22/1, 147-167.

(2010): Púrpura. Del mercado al poder, Madrid.

(2011): Dones del cielo Abeja y miel en el Mediterráneo antiguo, Madrid.

Fletcher Valls, D. (1953): Inscripciones ibéricas del Museo de Prehistoria de Valencia, (=Estudios Ibéricos 2), Valencia.

Fuentes Albero, M. M. - Hurtado Mullor, T. - Moreno Martín, A. (2004): "Nuevas aportaciones al estudio de la apicultura en época ibérica", Recerques del Museu d'Alcoi 13, 181-200.

Gallazzi, C. - Kramer, B. (1998): "Artemidor im Zeichensaal. Eine Papyrusrolle mix text, landkarte und skizzenbüchern aus späthellenisticher Zeit", Archiv für Papyrusforschung 44, 189-208.

García VARGas, E. (2004): "Las pesquerías en la Bética durante el Imperio Romano y la producción de púrpura" [en] C. Alfaro - J. P. Wild - B. Costa (eds.), Purpureae Vestes I. Textiles y tintes del Mediterráneo en época romana. Actas del I Symposium Internacional sobre Textiles y Tintes del Mediterráneo en época romana (Ibiza 8 al 10 de noviembre, 2002), Valencia, 219-235.

Garrido RoIz, J. P. (1988) "Influencias foráneas en el círculo fenicio del Atlántico:El complejo cultural de Huelva en el periodo orientalizante", [en] Actas del I Congreso Internacional "El Estrecho de Gibraltar", tomo 1, Ceuta, 399-406.

Garrido RoIz, J. P. - ORTA. E. (eds.) (1994): El hábitat antiguo de Huelva (periodos orientalizante y arcaico.La primera excavación arqueológica de la calle del Puerto, (=Excavaciones arqueológicas de España 171), Madrid.

GonzÁLEZ WAGNER, C. (1988): “Gadir y los más antiguos asentamientos fenicios al este del Estrecho", [en] Actas del I Congreso Internacional "El Estrecho de Gibraltar", Ceuta, 419-428.

Gozalbes Cravioto, E.

(1981):"Tarifa en el Mundo Antiguo", Aljaranda, 1-15.

(2001): “Calpe y el Estrecho de Gibraltar en el Geógrafo Artemídoro de Éfeso", Almoraima: Revista de estudios campo gibraltareños 25, 105-114. 
(2005): "El final del rey Ptolomeo de las Mauretaniae”, Gerión 23/1, 189-204.

(2007): "Las islas atlánticas de la Púrpura (Pl. NH. VI 201)", Anuario de Estudios Atlánti$\cos 53,273-296$.

Gsell S. (1927): Histoire Ancienne d'Afrique du Nord, Paris.

Hernández García, J. DE Dios

(2004): "Un posible taller de purpura del s. I d.C. localizado en Águilas, Murcia (España)" [en] C. Alfaro - J. P. Wild - B. Costa (eds.), Purpureae Vestes I. Textiles y tintes del Mediterráneo en época romana. Actas del I Symposium Internacional sobre Textiles y Tintes del Mediterráneo en época romana (Ibiza 8 al 10 de noviembre, 2002), Valencia, 215-218.

(2005): "Un taller de púrpura del s. I d.C. localizado en Águilas. Excavación en calle Francisco Rabal, 5 (Águilas, Murcia)", Verdolay 9, 165-176.

Jodin, A. (1967): Les Establissements Du Roi Juba II Aux Iles Purpuraires (Mogador), Tanger.

Kotula, I. T. (1965): "Encore sur la mort de Ptolémée, roi de Maurétanie”, Archeologia 15, 76-94.

Lillo CARPio, P. (1994): "Pix y oleumligni, productos industriales básicos en la antiigüedad y su pervivencia”, Revista murciana de antropología 1,109-119.

Mangas, J. (1988): "Iuba II de Mauritania, magistrado y patrono de ciudades hispanas", [en] Actas del I Congreso Internacional El Estrecho de Gibraltar (Ceuta, 1987), tomo 1, Madrid, 731-739.

Morais, R. (2006): "Potes meleiros e colmenas em cerâmica: una tradicâo milenar", Sagvntvm. Papeles del Laboratorio de Arqueología 38, 149-161.

Morales MuÑiz, A. - Roselló Izquierdo, E. (1988): “La riqueza del Estrecho de Gibraltar como Inductor potencial del proceso de colonización de la península Ibérica”, [en] Actas del I $I^{\circ}$ Congreso Internacional El Estrecho de Gibraltar (Ceuta, 1987), tomo 1, Madrid, 447-457.

Molina García, J. (1989): "Nuevo tipo cerámico en el ajuar ibérico: embudo para miel (consideraciones arqueológico-etnográficas)", Rev.Murgetana 78, 11-18.

MüLler, C. (1854): Geographi graeci minores, Paris.

Nordström, S. (1969-71): "La ceramique peinte Iberique de la province d'Alicante", [en] I \& II, Acta universitatis Stockholmiensis - Stockholm studies in classical archaeology VI \& VIII, Stockholm, 78-180.

Rodriguez Neila, J. F. (1994): “El epígrafe CIL II 2242 de Corduba y las "locationes” de propiedades públicas municipales”, [en] C. González Román (coord.), La sociedad de la Bética: contribuciones para su estudio, 425-460.

SÁEz Fernández, P. (1991): “Consideraciones sobre el cultivo del olivo en la Bética hispanoromana. Aspectos económicos y sociales”, [en] C. González Román (coord.), La Bética en su problemática histórica, 277-298.

SiRET, L. (1907): Villaricos y Herrerías. Antigüedades púnicas, romanas y visigodas, (Memorias de la Real Academia de la Historia 10-11), Madrid.

Soria CombadierA. L. (2000): "Evidencias de producción de miel en la comarca del Júcar (Albacete) en época ibérica", [en] Ibers. Agricultors, artesans i comerciants. III Reunió sobre Economia en el Món Ibèric (=Saguntum: Papeles del Laboratorio de Arqueología de Valencia $n^{\circ}$ extra 3), 177-180. 
Torres, J. R. (2004): “Evidènces d'elaboració de porpra i fabricació de teixits a Sa Caleta (Eivissa)", [en] C. Alfaro - J. P. Wild - B. Costa (eds.), Purpureae Vestes I. Textiles y tintes del Mediterráneo en época romana. Actas del I Symposium Internacional sobre Textiles y Tintes del Mediterráneo en época romana (Ibiza 8 al 10 de noviembre, 2002), Valencia, 165-174.

VÁzQuez Hoys, A. M. (1991): "La miel, alimento de la eternidad”, [en] J. Ma Blázquez - S. Montero (coords.), Alimenta estudios en Homenaje al Dr. Michel Ponsich, (=Anejos de Gerión 3), Madrid, 61-93.

Vidal la Blanche, P. (1902): Les purpuraires du roi Iuba II, Melanges Perrot, Paris.

WiLson, A. I. (2004): “Archaeological evidence for textile production and dyeing in Roman North Africa", [en] C. Alfaro - J. P. Wild - B. Costa (eds.), Purpureae Vestes. Textiles y tintes del Mediterráneo en época romana, Actas del I Symposium Internacional sobre Textiles y Tintes del Mediterráneo en época romana (Ibiza 8 al 10 de noviembre, 2002), Valencia, 155-64. 